\title{
Review \\ Treatment options in patients with rheumatoid arthritis failing initial TNF inhibitor therapy: a critical review
}

\author{
Andrea Rubbert-Roth ${ }^{1}$ and Axel Finckh²
}

\author{
1Department of Internal Medicine, University of Cologne, Josef-Stelzmann-Strasse, 50924 Cologne, Germany \\ 2Division of Rheumatology, Department of Internal Medicine, University Hospital of Geneva, 26 Avenue Beau-Sejour, 1211 Geneva 14, Switzerland
}

Corresponding author: Andrea Rubbert-Roth, andrea.rubbert@uk-koeln.de

Published: 6 April 2009

This article is online at http://arthritis-research.com/supplements/11/S1

(c) 2009 BioMed Central Ltd
Arthritis Research \& Therapy 2009, 11(Suppl 1):S1

(doi:10.1186/ar2666)

they are in a state of low disease activity, suggesting that achieving remission should be the ultimate goal $[5,6]$.

Disease-modifying antirheumatic drugs (DMARDs) are the mainstay of treatment for RA. Methotrexate is the most commonly used agent in this class, and it is effective on standard clinical measures of disease activity [7], costeffective and comparatively well tolerated. The development of biologic agents represented a major advance in the treatment of RA. The targets of biologic agents are interactions between the immune effector cells (T lymphocytes, B lymphocytes and macrophages), which are responsible for inflammation and structural damage in affected joints, and the signalling molecules involved in their activation. The first approved biologic agents for the treatment of RA were inhibitors of tumour necrosis factor (TNF). There are now three agents available in this treatment class: etanercept, infliximab and adalimumab. These agents are very effective at improving the signs and symptoms, and at slowing or preventing structural damage in patients with RA [8-14]. Newer TNF inhibitors are also in clinical development for the treatment of RA and include golimumab [15] and certolizumab pegol [16]. Both of these agents are effective at improving signs and symptoms of disease, and prevention of structural damage has been reported for certolizumab pegol $[17,18]$.

However, anti-TNF agents are not effective in all patients. About $30 \%$ of patients treated with a TNF inhibitor failed to achieve an improvement of $20 \%$ in American College of Rheumatology criteria (ACR20; primary failure or inefficacy) $[11,13,14]$, and more patients lose efficacy during therapy (secondary failure or acquired therapeutic resistance) [19] or

ACR20 $=20 \%$ improvement in American College of Rheumatology criteria; ATTAIN = Abatacept Trial in Treatment of Anti-TNF INadequate responders; $\mathrm{Cl}=$ confidence interval; DAS28 = 28-joint Disease Activity Score; DMARD = disease-modifying antirheumatic drug; EULAR = European League Against Rheumatism; HAQ = Health Assessment Questionnaire; LLN = lower limit of normal; RA = rheumatoid arthritis; ReAct = Research in Active rheumatoid arthritis; REFLEX = Randomised Evaluation oF Long-term Efficacy of rituXimab in rheumatoid arthritis; TB = tuberculosis; TNF $=$ tumour necrosis factor. 
experience adverse events following treatment with a TNF inhibitor.

Until recently, therapeutic options were limited for patients not responding satisfactorily to TNF inhibitors, and who typically have failed many conventional DMARDs and combinations of DMARDs. Switching from one TNF inhibitor to another has become an established treatment approach for patients who failed or were intolerant of treatment with an initial TNF inhibitor. This is largely because of physician experience and familiarity with the efficacy and safety profile of these products that has developed over the past several years, and the strong evidence that TNF inhibitors are potent in terms of slowing disease progression. Despite a similar mode of action within the TNF inhibitor class, the rationale behind switching these agents resides in variations in bioavailability, differences in the stability of the TNF-inhibitor complex or the potential occurrence of drug-neutralizing antibodies [20]. Although formally none of the available TNF inhibitors is currently approved for this indication, a recent survey of US-based rheumatologists showed that over $94 \%$ of respondents reported switching patients from one TNF inhibitor to another [21]. However, this survey was conducted at a time when biologics with a different mode of action were not yet available.

Recently, biologic agents with novel mechanisms of action have been approved for use in patients with RA, therefore increasing the number of therapeutic options for patients with inadequate response or intolerance to a first TNF inhibitor. Rituximab, a monoclonal antibody directed against $\mathrm{CD} 2 \mathrm{O}^{+} \mathrm{B}$ cells, induces transient depletion of $B$ cells and was recently approved for the treatment of adult patients with severe active RA who have exhibited an inadequate response to or were intolerant of one or more TNF inhibitors in combination with methotrexate [22]. Abatacept, a selective inhibitor of T-cell costimulation, has been approved for the treatment of patients who have exhibited an inadequate response to or were intolerant of one or more DMARDs or TNF inhibitors in the USA, or one or more TNF inhibitors only in Europe. Tocilizumab, a chimeric monoclonal antibody blocking interleukin-6mediated signal transduction, was recently studied in patients not responding to TNF inhibitors [23], and the European Commission has recently approved its use in this indication.

Optimal treatment strategies have yet to be defined for patients who have exhibited an inadequate response to or were intolerant of an initial TNF inhibitor, because there have been no randomized, prospective, head-to-head trials comparing the strategy of cycling between TNF inhibitors versus using an agent with a different mechanism of action.

The aim of this review is to appraise the current evidence in support of the available treatment strategies in patients with an inadequate response or intolerance to an initial TNF inhibitor.

\section{Efficacy \\ Signs and symptoms}

Data supporting cycling between TNF inhibitors are limited in terms of both quantity and quality. Well controlled switching trials are limited; the vast majority of current data comes from open-label, retrospective or prospective observational studies.

Several observational studies have demonstrated an improvement in disease activity in patients who have not responded to a TNF inhibitor when switched to another TNF inhibitor. However, the results of these studies may be biased by a phenomenon known as 'regression to the mean' in that, because patients tend to be treated with a second agent at the height of their disease activity, there is a greater than 50-50 likelihood that disease activity will start improving after the intervention purely by chance [24].

Results from several large studies also indicate that efficacy may decline following cycling to a second TNF inhibitor [25-30] (Figures 1 and 2). A recent Swedish survey [31] identified a reduction in response when patients were switched to their second TNF inhibitor compared with TNF inhibitor-naïve patients, and a more marked reduction when patients were switched to a third TNF inhibitor. An ACR20 response was achieved by $51 \%$ of first-time switchers ( $n=337)$ and only by $35 \%$ of second-time switchers $(n=36)$. The corresponding ACR50 rates were 27\% and $18 \%$, respectively. The European League Against Rheumatism (EULAR) good or moderate rates were $71 \%$ and $58 \%$, and EULAR good rates were $25 \%$ and $9 \%$, respectively. The 28-joint Disease Activity Score (DAS28) remission rates were $16 \%$ and $6 \%$, respectively.

The Open-label, Pilot Protocol of patients with rheumatoid arthritis who Switch to Infliximab after an incomplete response to Etanercept (OPPOSITE) trial [32] was a small, randomized study, involving 28 patients, which suggested a more favourable outcome in patients who switched to infliximab. However, the majority of patients did not achieve an ACR50 response. Efficacy results with subsequent TNF inhibitor treatment appear to differ according to the reason for switching [25,33]. Of 6,739 patients with RA whose primary treatment with a TNF inhibitor (adalimumab, etanercept or infliximab) was recorded in a large UK national biologics register, 856 were switched to a second TNF inhibitor because of inefficacy (503 patients) or adverse events (353 patients) [33]. Patients who had discontinued the first inhibitor because of inefficacy were more likely to fail treatment with a second inhibitor for the same reason (hazard ratio $=2.7,95 \%$ confidence interval $[\mathrm{Cl}]=2.1$ to 3.4 ) rather than toxicity (hazard ratio $=1.1,95 \% \mathrm{Cl}=0.9$ to 1.5 ). Similarly, rates of drug discontinuation for adverse events were higher in patients who had previously discontinued because of intolerance (hazard ratio $=2.3,95 \% \mathrm{Cl}=1.9$ to 2.9) than in those who had previously discontinued because of inefficacy (hazard ratio $=1.2,95 \% \mathrm{Cl}=0.8$ to 1.6 ). 


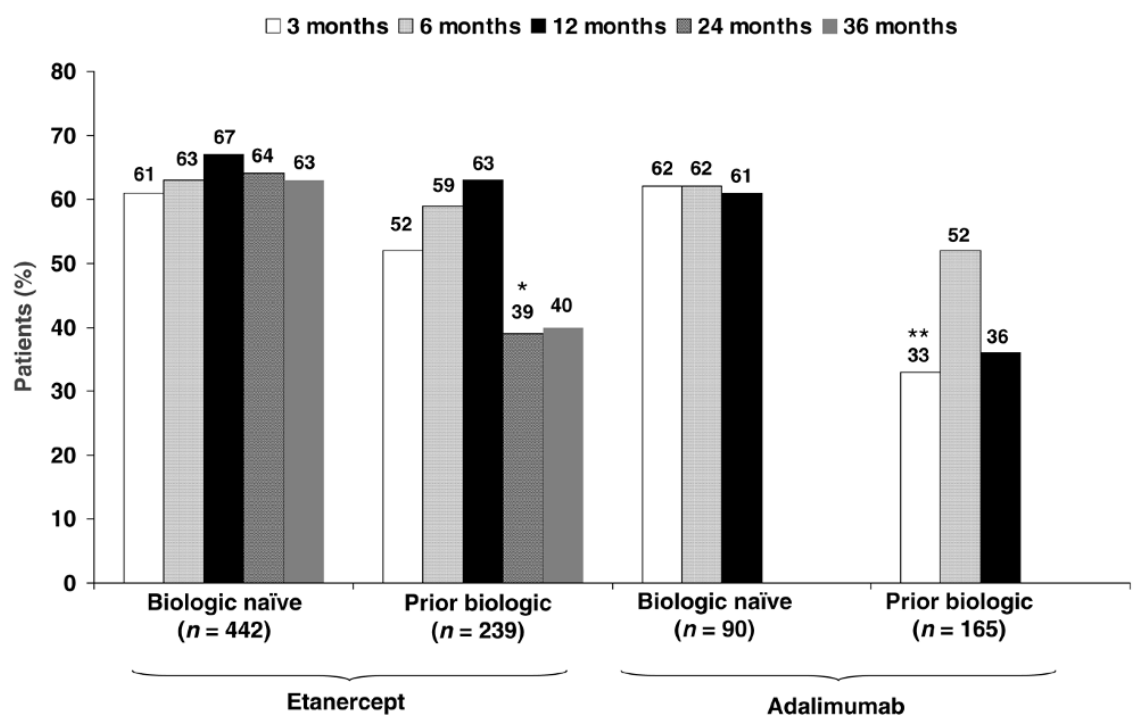

ACR20 response in patients with and without prior TNF inhibitor treatment. ${ }^{\star} P=0.028,{ }^{\star \star} P<0.0015$. Data from Kristensen et al. [28]. ACR20, $20 \%$ improvement in American College of Rheumatology criteria; TNF, tumour necrosis factor.

Figure 2

$\square$ Good response $\square$ Moderate response $\square$ No response

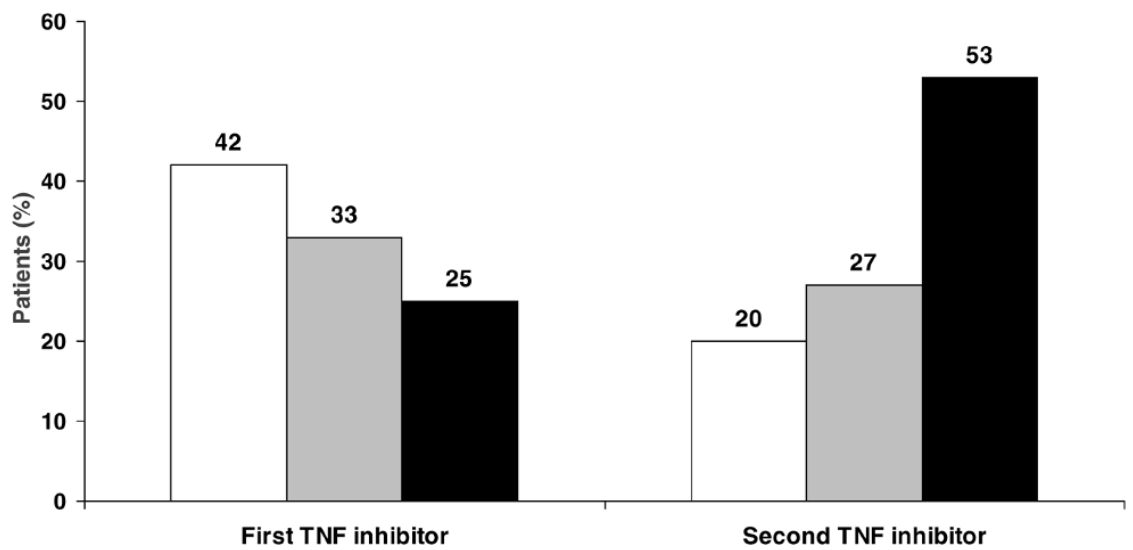

EULAR response following treatment with one or two TNF inhibitors. Data from Navarro et al. [29]. EULAR, European League Against Rheumatism; TNF, tumour necrosis factor.

Those patients failing TNF inhibitor therapy because of lack of efficacy can be subdivided into those who never achieved an adequate response (primary failure or inefficacy) and those who lost response over time (secondary failure or acquired therapeutic resistance). In general, a second TNF inhibitor appears to be more effective in patients with a history of secondary failure rather than primary failure, but some heterogeneity has been seen in small studies. For instance, in a large cohort study, RA patients were permitted to switch to adalimumab after prior treatment with etanercept and/or infliximab (Research in Active rheumatoid arthritis [ReAct])
[25]; responses to adalimumab appeared to be lower in patients with primary failure than in patients with secondary failure or intolerance (Figure 3). A preliminary report from a Dutch registry included 128 patients who were switched because of primary $(n=35)$ or secondary $(n=41)$ failure or intolerance $(n=50)$ [34]. After the switch, all groups (including primary nonresponders) exhibited significant improvement in DAS28 compared with baseline: -1.77 for primary nonresponders, -1.18 for secondary nonresponders and -1.54 for patients who were switched because of adverse events $(P=0.189)$. Furthermore, in 43 patients switched to 


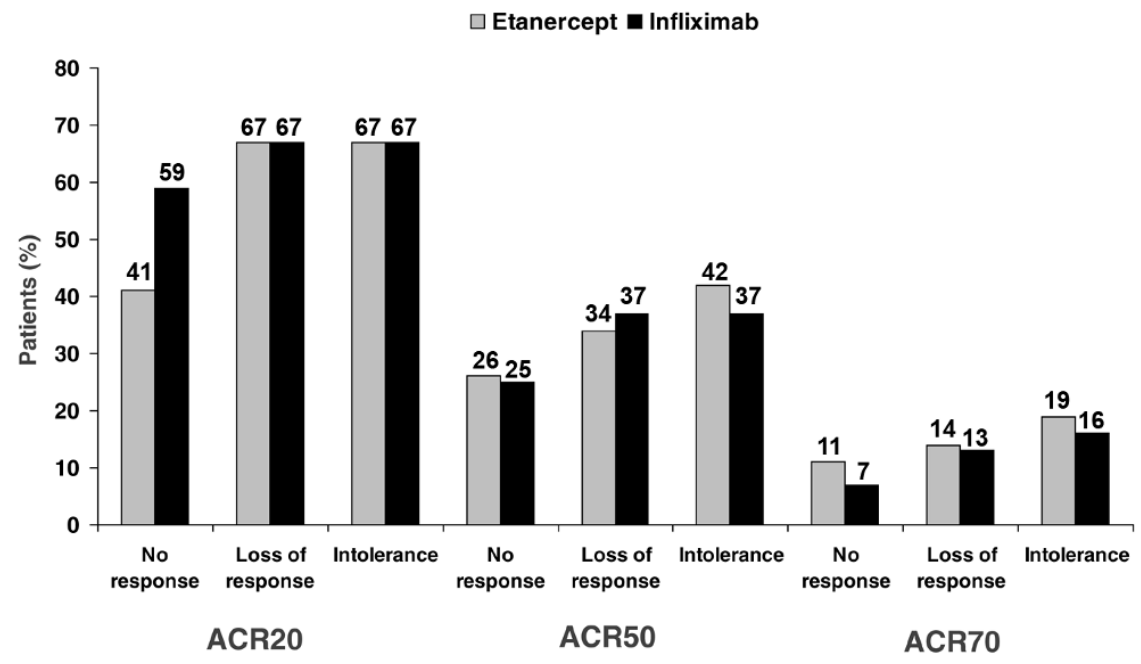

Switching TNF inhibitors: ACR response 12 weeks after switching to adalimumab. Data from Bombardieri et al. [25]. ACR, American College of Rheumatology; TNF, tumour necrosis factor.

another TNF inhibitor after adalimumab failure, successful treatment was more likely if adalimumab had been stopped because of secondary failure or intolerance [35]. The proportions of patients with EULAR good response in each group were $4.5 \%$ in the 22 patients with primary failure, $27.3 \%$ in patients with secondary failure and $30 \%$ in patients who were intolerant of adalimumab. In contrast, some other studies have indicated that response to a second TNF inhibitor may be greater in the cohort of patients with primary rather than secondary failure [36]. In a study in which 95 patients were switched from infliximab/methotrexate therapy to etanercept (34 because of primary failure, 38 because of secondary failure and 23 because of intolerance), achievement of ACR20, ACR50 and ACR70 responses was greatest in the patients with primary infliximab failure.

Two large studies $[37,38]$ indicated that the 'drug survival' time of a second TNF inhibitor is reduced in patients who had received a prior TNF inhibitor agent. In a survey of 4,760 patients $(68 \%$ with RA, $11 \%$ with ankylosing spondylitis, $10 \%$ with psoriatic arthritis and $11 \%$ with other chronic inflammatory conditions) receiving TNF inhibitors [37], the 1-year and 2-year drug survival rates were $83 \%$ and $75 \%$, respectively, and were even lower in patients receiving a second TNF inhibitor ( $n=441$ patients; $68 \%$ and $60 \%$ at 1 and 2 years, respectively; Figure 4). A similar trend was observed for the third TNF inhibitor, but because the numbers were too small ( $n=47$ patients) to permit meaningful analysis, these data are not shown. A survey of TNF inhibitornaïve patients and those who had received a TNF inhibitor previously was undertaken, and the duration of treatment for $50 \%$ and $75 \%$ of patients who remained on therapy was compared [38]. The $50 \%$ drug survival time was reduced from 26.8 months in the TNF inhibitor-naïve patients to 17.6 months in the patients who had received a TNF inhibitor previously $(P=0.04)$. The corresponding values for $75 \%$ drug survival were 6.9 and 5.3 months, respectively. Thus, mean drug survival times were significantly reduced in patients who had previously received one or more TNF inhibitors.

Treatment with golimumab, a new TNF inhibitor that is under clinical development, produced a significantly greater ACR20 response after 24 weeks when compared with placebo in patients who had previously been treated with at least one other TNF inhibitor and then discontinued because of lack of efficacy (38.9\% with golimumab $50 \mathrm{mg}$ and $100 \mathrm{mg}$ combined versus $17.7 \%$ with placebo; $P<0.001$ ) [15]. However, the relative difference in response rates compared with placebo in this patient population was relatively small compared with most other earlier randomized controlled trials of TNF inhibitors in similar populations of patients naïve to TNF inhibitors or other biologics [11-14,39].

Overall, these findings suggest that the decline in efficacy after a switch to a second TNF inhibitor may in part be due to a class effect and also to a channelling bias favouring patients with more severe disease. Thus, the rationale for introducing agents with a different mode of action may be to overcome issues related to class, particularly in cases of primary failure or recurrence of class-associated adverse events.

Rituximab, administered as two $1,000 \mathrm{mg}$ infusions 14 days apart, was shown to be effective in patients with an inadequate response to TNF inhibitors in a well designed, 
Figure 4

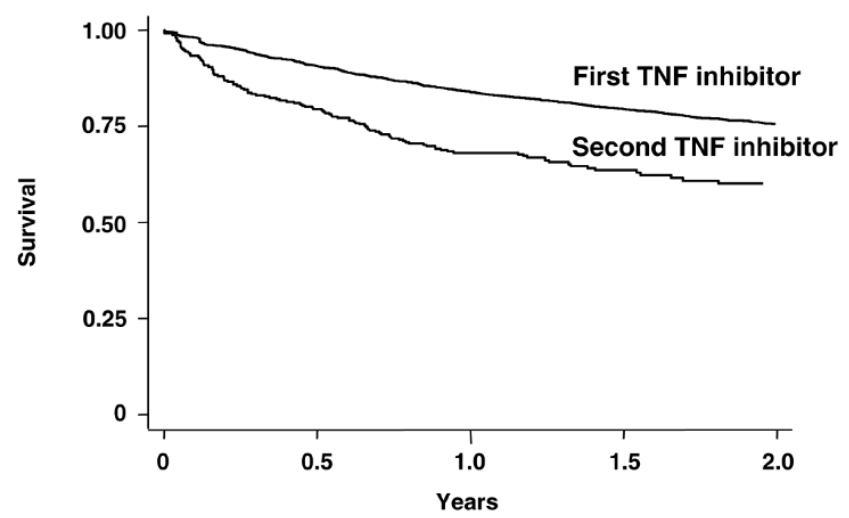

Survival curve for TNF inhibitors in BIOBADASER during the first 2 years of use. Reproduced from Gomez-Reino et al. [37], with permission from BioMed Central Ltd. BIOBADASER, Spanish Society of Rheumatology Database on Biologic Products; TNF, tumour necrosis factor.

randomized, placebo-controlled study (Randomised Evaluation oF Long-term Efficacy of rituXimab in rheumatoid arthritis [REFLEX]) [40]. In patients with active RA and an inadequate response to TNF inhibitors, repeated courses of rituximab yielded sustained or improved efficacy compared with original baselines (Figure 5). In addition, achievement of EULAR good response at week 24 was maintained or improved with repeated courses of rituximab [41]. The efficacy of rituximab has also been shown to be superior when it is used in patients who have exhibited an inadequate response to a single TNF inhibitor when compared with patients with failures to two or more TNF inhibitors (Figure 6) [42]. Observational studies have generally confirmed the findings from clinical trials. An analysis from a large practice-based regional registry confirmed that rituximab therapy significantly improved disease activity (DAS28; $P<0.0005$ ) at 3, 6, 9 and 12 months in 114 patients with RA and an inadequate response to at least one previous TNF inhibitor. At 6 months and in a total of 59 patients, a moderate to good EULAR response was seen in $62 \%$ of patients, of whom $23 \%$ had a good response, and remission occurred in 18\% [43]. Importantly, repeat treatment with rituximab produced sustained efficacy for at least 6 months [44].

Superior efficacy of abatacept ( $10 \mathrm{mg} / \mathrm{kg}$ intravenous infusion on days 1, 15 and 29, and then every 28 days thereafter) combined with at least one DMARD relative to placebo has been demonstrated in patients exhibiting an inadequate response to TNF inhibitor therapy in the Abatacept Trial in Treatment of Anti-TNF INadequate responders (ATTAIN) study [39]. At 6 months, the ACR20 response rate was $50.4 \%$ in the abatacept group versus $19.5 \%$ in the placebo group $(P<0.001)$. The ACR50 and ACR70 response rates were also significantly higher in the abatacept group than in the placebo group (ACR50 response: $20.3 \%$ versus $3.8 \%$,
$P<0.001 ;$ ACR70 response: $10.2 \%$ versus $1.5 \%$, $P=0.003$; Figure 7). Analysis of the extended, open-label period of ATTAIN revealed that sustained improvements in ACR responses were achieved after 2 years of treatment with abatacept [45].

\section{Patient-reported disability}

Various groups, including EULAR, ACR and the Outcome Measures in Rheumatology Clinical Trials group, recognize that patient-reported outcome measures are important in developing an understanding of patients' experience of their disease. One such measure, the Health Assessment Questionnaire (HAQ) disability index, captures self-perceived disability. Scores range from 0 to 3, with higher scores reflecting increased disability. Improvements in this measure of disability have been used in a number of studies to determine responses to various treatment strategies.

The effect of switching between TNF inhibitors was analyzed in patients with an inadequate response to a first TNF inhibitor and in whom HAQ was measured at the time of nonresponse and 12 months later [46]. Patients were classified into three groups based on treatment during the subsequent 12 months: those receiving no further TNF inhibitor therapy ('stoppers', $n=148$ ), those who switched to a second TNF inhibitor ('switchers', $n=331$ ) and those who continued on their first TNF inhibitor therapy for at least a further 9 months ('stayers', $n=389$ ). The proportion of patients who achieved a minimum clinically important difference (defined as an improvement in $\mathrm{HAQ}$ of $\leq 0.22$ units) was higher for switchers (36\%) than for stayers (31\%) or stoppers (22\%; $P<0.01$ versus switchers). Although these data suggest that switching to a second TNF inhibitor is more beneficial than discontinuing treatment and receiving no biologic therapy during the subsequent 12 months, the majority of patients who switched did not experience a clinically significant improvement regarding functionality. Of note, patients with more advanced disease and established structural damage will be less likely to be able to regain full functional capacity [47].

The effect on HAQ has also been determined in patients with inadequate response to TNF inhibitors and treated with other biologic agents. In the REFLEX study [48], more patients treated with rituximab plus methotrexate achieved a minimum clinically important difference after 6 months compared with patients treated with placebo plus methotrexate $(63.8 \%$ versus $32.5 \%$; $P<0.0001)$. In addition, in the ATTAIN study more patients in the abatacept group than in the placebo group $(47.3 \%$ versus $23.3 \% ; P<0.001)$ had a clinically meaningful improvement in $\mathrm{HAQ}$ (in this instance defined by an improvement in $\mathrm{HAQ}$ of $\leq 0.3$ units from baseline) [45].

\section{Radiographic data}

The efficacy of all currently available TNF inhibitors in terms of inhibiting radiographic progression is well established in 
$\square$ 1st course $\square$ 2nd course $\square$ 3rd course $(n=96)$

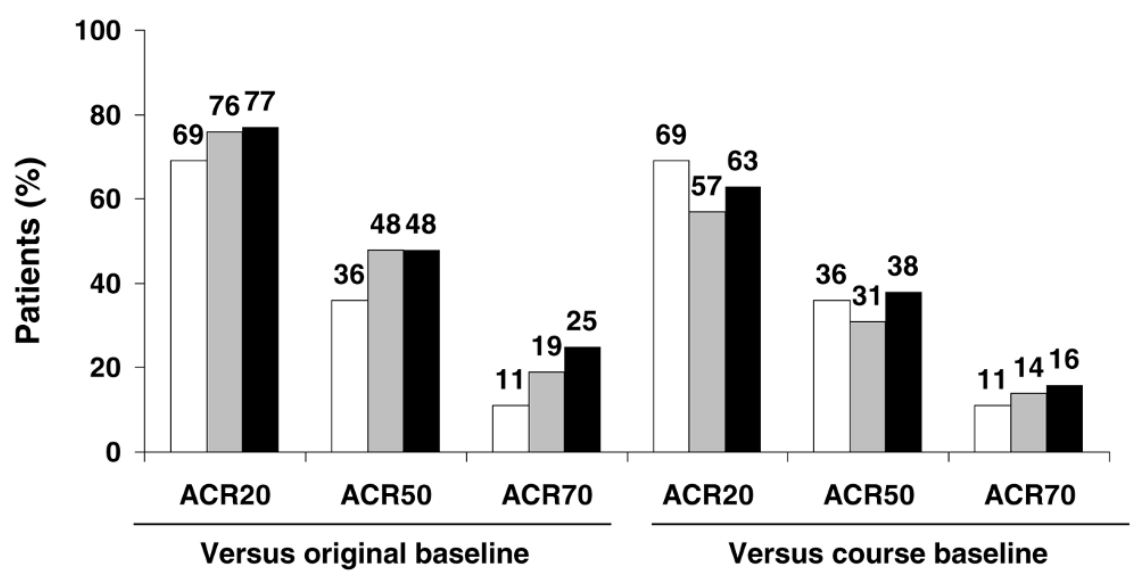

ACR responses at week 24 in patients treated with multiple courses of rituximab. Data from Keystone et al. [44]. ACR, American College of Rheumatology.

\section{Figure 6}

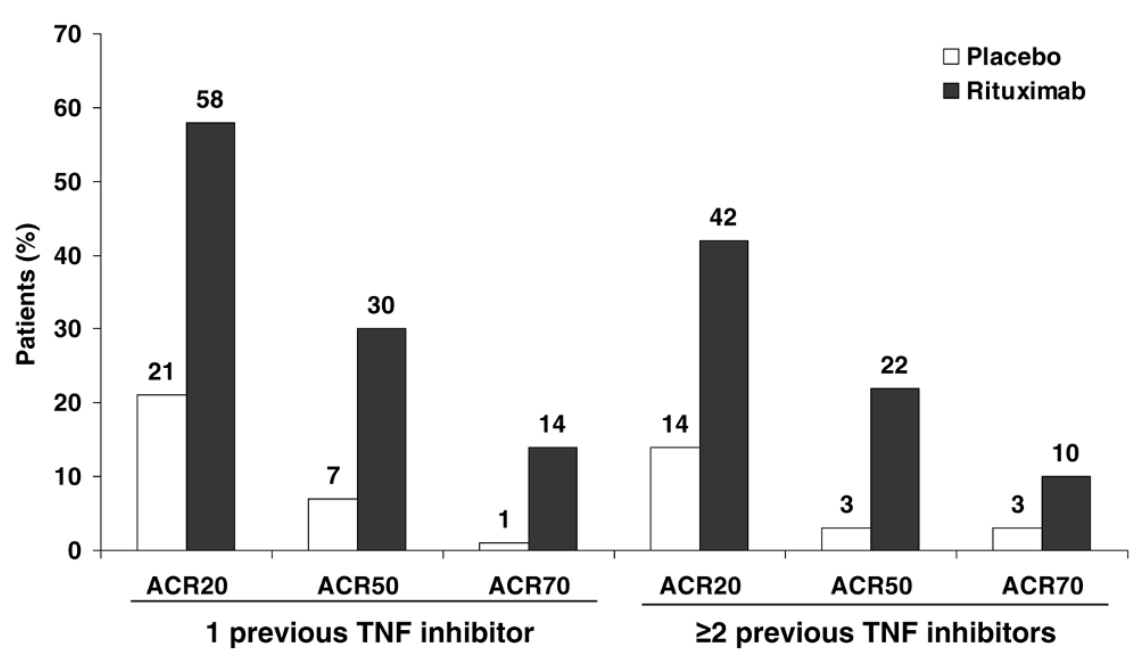

ACR response rate with rituximab: impact of number of previous TNF inhibitors. The ACR response rate is superior in patients with an inadequate response to one TNF inhibitor in comparison with patients who have received treatment with two or more previous TNF inhibitors. Data from Kremer et al. [42]. ACR, American College of Rheumatology; TNF, tumour necrosis factor.

patients with inadequate response to DMARDs and/or in methotrexate-naïve patients. However, no formal studies have demonstrated the efficacy of a second TNF inhibitor in inhibiting radiographic progression in patients who responded inadequately to prior TNF inhibitor treatment. However, given the capacity of TNF inhibitors to inhibit radiographic progression, even in patients not exhibiting a clinical response, it is unlikely that this would be substantially different in patients switched to a second TNF inhibitor.
Rituximab is thus far the only agent that has formally demonstrated significant slowing of structural joint damage in RA patients with an inadequate response to or who are intolerant of TNF inhibitors [49] (Figure 8). Results from the REFLEX study in 517 patients with RA showed that rituximab plus methotrexate treatment produced a significant reduction in joint damage progression compared with placebo plus methotrexate. Significant reductions were shown from baseline to 56 weeks for rituximab plus methotrexate compared with 


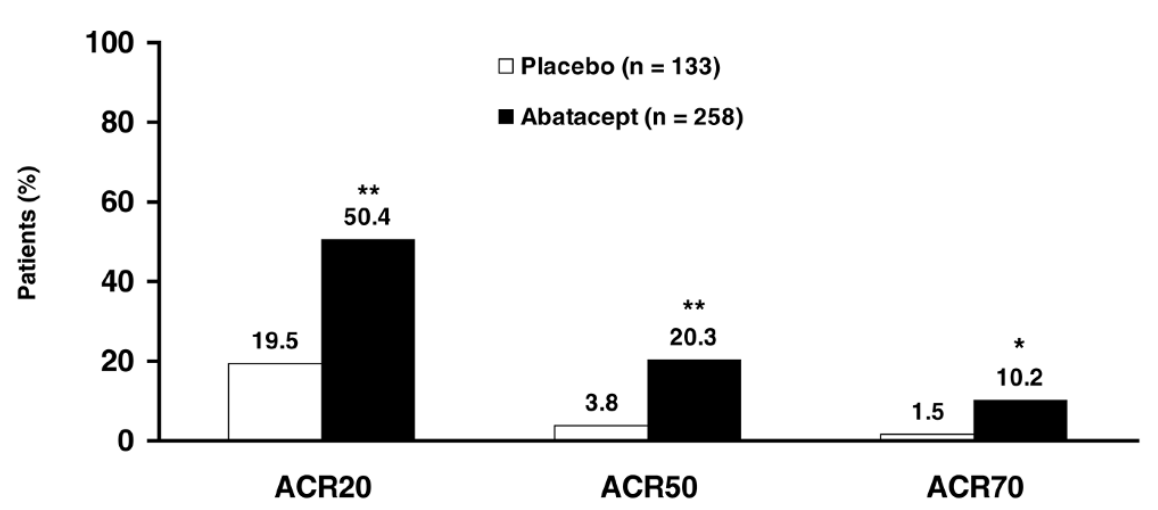

ACR response rates with abatacept at 6 months in the ATTAIN study. ${ }^{\star} P=0.003,{ }^{\star \star} P<0.001$. Reproduced with permission from Genovese et al. N Engl J Med 2005, 353:1114-1123 [39]. Copyright (C) 2005 Massachusetts Medical Society. All rights reserved. ACR, American College of Rheumatology; ATTAIN, Abatacept Trial in Treatment of Anti-TNF INadequate responders.

placebo plus methotrexate in the following measures: Genant-modified Sharp score ( 1.00 versus $2.31 ; P=0.005)$, the erosion score $(0.59$ versus $1.32 ; P=0.011)$ and the joint space narrowing score ( 0.41 versus $0.99 ; P<0.001)$. This difference is remarkable, given that the majority of patients in the placebo group (81\%) received at least one course of rituximab, because from weeks 16 to 24 patients who had failed to respond to treatment $(<20 \%$ improvement in swollen joint counts) could receive rescue therapy. These findings have now been extended to 2 years [50]. Furthermore, rituximab has been shown to inhibit radiographic progression independent of clinical response in this patient population [51]. As with TNF inhibitors [52], these findings suggest that disease activity and radiographic progression can be disconnected and are independent outcomes.

There are no specific radiographic data for abatacept in the population of patients who respond inadequately to TNF inhibitors. However, inhibition of radiographic progression has been shown in inadequate responders to DMARDs in the Abatacept in Inadequate responders to Methotrexate (AIM) study [53]. Although golimumab and tocilizumab have been studied in this patient population, no radiographic outcomes have yet been presented.

\section{Head-to-head studies}

No large, double-blind, randomized, head-to-head studies have been conducted in a population of patients exhibiting inadequate response to a TNF inhibitor. A recently reported observational study [54] indicated that, in a population of patients with inadequate response to one or more TNF inhibitors, rituximab may be more effective at controlling disease activity than switching to an alternative TNF inhibitor (Figure 9). A total of 116 patients with RA met the inclusion criteria: 50 patients received rituximab (two $1,000 \mathrm{mg}$ infusions) and 66 received a second or third TNF inhibitor (49\%, $27 \%$ and $24 \%$ were treated with adalimumab, etanercept and infliximab, respectively). The results of this observational study of patients enrolled in the Swiss registry found that, at 6 months, the decrease in DAS28 was greater in patients treated with rituximab $(-1.61,95 \% \mathrm{Cl}=-1.97$ to -1.25$)$ than in those treated with an alternative TNF inhibitor $(-0.98,95 \%$ $\mathrm{Cl}=-1.33$ to -0.62 ). Of note, higher numbers of prior TNF inhibitors were reported for rituximab-treated patients than for those treated with an alternative TNF inhibitor (median two versus one; $P=0.001$ ), whereas both groups (rituximab and alternative TNF inhibitor) were similar with regard to other parameters at baseline.

These findings were confirmed in a recent, extended analysis of more than 300 patients from the same cohort [55]. This analysis further demonstrated that the relative benefit of rituximab varied with the reason for switching from a prior TNF inhibitor. When the motive for switching was lack of effect with a previous TNF inhibitor, then the evolution of DAS28 was significantly better for rituximab than for the alternative TNF inhibitor. However, when the motive for switching was another cause (such as an adverse event), then the evolution of DAS28 was similar for rituximab and the alternative TNF inhibitor. These findings were not significantly modified by DMARD co-therapy, by the type of TNF inhibitor or by the number of previous TNF inhibitors used.

This strategy is also supported by data from another smaller observational study conducted in the UK in patients with RA exhibiting an inadequate response to a TNF inhibitor [56]. After 3 months, the change in DAS28 was more favourable in the group who received rituximab $(-3.03 ; n=15$ patients) than in the group who received an alternative TNF inhibitor $(-1.5 ; n=24$ patients).

No head-to-head studies in a TNF inadequate responder population utilizing abatacept or tocilizumab have yet been conducted. 


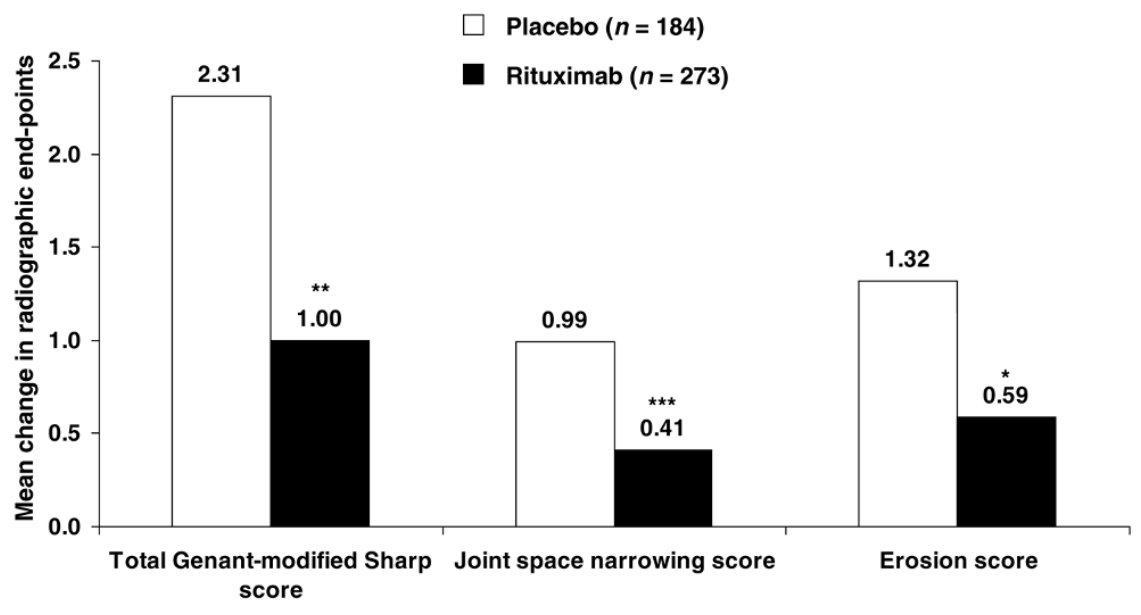

Change at week 56 in radiographic end-points in TNF inadequate-response patients treated with rituximab. ${ }^{\star} P=0.011,{ }^{* \star} P=0.005,{ }^{\star \star \star} P<0.001$. Reproduced from Keystone et al. Arthritis Rheum 2008, 59:785-793 [48], with permission from BMJ Publishing Group Ltd. TNF, tumour necrosis factor.

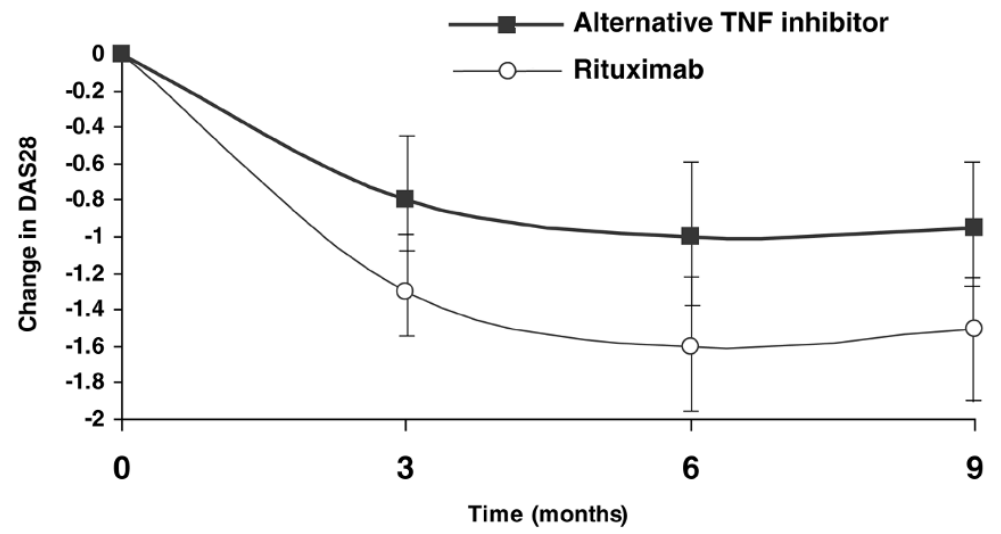

Change in DAS28: rituximab versus switching to an alternative TNF inhibitor. DAS28, 28-joint Disease Activity Score; TNF, tumour necrosis factor. Reproduced from Finckh et al. Arthritis Rheum 2007, 56:1417-1423 [54]. Reprinted with permission of John Wiley \& Sons, Inc.

\section{Safety and tolerability}

\section{Tumour necrosis factor inhibitors}

TNF inhibitors have been indicated for the treatment of RA for more than 10 years and, as a result, they have a well established safety profile.

There have been rare reports of opportunistic infections, including tuberculosis (TB), which makes appropriate TB screening mandatory before starting TNF therapy. In addition, there have been rare reports of worsening pre-existing heart failure and the occurrence of demyelinating diseases in patients who have received TNF inhibitors [57,58]. Data from the National Databank of Rheumatic Diseases suggested a modest increase in lymphoma [59] and an increased risk for skin cancer in patients treated with TNF inhibitors [60]. Evidence for an increased risk for serious infections and a dose-dependent increase in malignancies was identified in a systematic review and meta-analysis of nine placebocontrolled trials of infliximab and adalimumab in patients with RA [61]. The meta-analysis involved 3,493 patients who had received TNF inhibitor treatment and 1,512 patients who received placebo. The pooled odds ratio for malignancies was $3.3(95 \% \mathrm{Cl}=1.2$ to 9.1$)$ and for serious infection was $2.0(95 \% \mathrm{Cl}=1.3$ to 3.1$)$, with a notably increased rate of basal cell carcinoma [61]. However, in a recent consensus statement it was suggested that treatment with TNF inhibitors does not appear to increase the risk for malignancy in patients with RA, although it is recommended that vigilance 
for the occurrence of lymphomas and other malignancies (including recurrence of solid tumours) remains in patients managed with TNF inhibitors [62]. Of note, hepatosplenic T-cell lymphomas were recently described in young patients with Crohn's disease [63], whereas in the Wegener's Granulomatosis Etanercept Trial (WGET) [64] an increased occurrence of solid malignancies was observed when etanercept was used in combination with cyclophosphamide in patients with Wegener's granulomatosis.

Because there may be a class effect, patients who fail treatment with a TNF inhibitor because of a tolerability or safety issue may be at increased risk for a similar safety problem on an alternative TNF inhibitor. The risk for developing an adverse event with a second TNF inhibitor increased twofold in patients switched because of an adverse event [33].

A study of hospitalization rates due to infection after TNF inhibitor therapy in 2,956 patients [65] indicated that, although the relative risk was greatest during the first year of treatment (1.74) and decreased to 1.04 in year 3 with continued therapy, switching to a second TNF inhibitor was associated with a second increase in relative risk $(2.10 ; 95 \%$ $\mathrm{Cl}=1.36$ to 3.27 ). Absolute rates of serious infections for the first TNF inhibitor were 4.5 serious infections per 100 person-years as compared with 7.0 per 100 person-years for the second TNF inhibitor. In the subset of 2,692 patients who had been hospitalized (not necessarily because of RA but who had it) before TNF inhibitor treatment, the incidence of infection during the period on the first TNF inhibitor was 5.4 per 100 person-years $(95 \% \mathrm{Cl}=4.7$ to $6.0 ; n=261$ infections), and that during the period on the second TNF inhibitor was 10.0 per 100 person-years $(95 \% \mathrm{Cl}=7.1$ to $16 ; n=26$ infections). These results are consistent with those from the ReAct study [25], a large cohort study that investigated the effects of switching from etanercept and/or infliximab to adalimumab. Serious infections occurred more frequently during treatment with adalimumab in patients who had received prior TNF inhibitor treatment (10.0 per 100 patient-years) compared with TNF inhibitor-naïve patients (4.9 per 100 patient-years) [25].

\section{Rituximab and abatacept}

Whereas rituximab has a well established safety profile in patients with B-cell lymphoma, data with regard to the repeated use of rituximab for chronic diseases such as RA are limited. The most frequent adverse events are infusion reactions, which are usually mild to moderate in intensity. The rate of serious infections was 5.2 per 100 patient-years in the rituximab group and 3.7 per 100 patient-years in the placebo group in the REFLEX study [40], which is consistent with that seen for patients treated de novo with a TNF inhibitor in randomized controlled trials $[9,14]$ and in observational studies $[66,67]$. Analysis of data from patients receiving up to seven treatment courses of rituximab, representing 2,438 patient-years of exposure, suggested no increase in the rate of serious infections with repeat courses [68]. The incidence of adverse events decreased from 88\% (931/1053) in rituximab-treated patients after course 1 to $81 \%, 72 \%$ and $65 \%$ after courses 2, 3 and 4, respectively. Serious adverse events followed a similar pattern, with the incidence of acute infusion reactions (first infusion, each course) also reducing with repeat courses [68].

Safety data from the 6-month ATTAIN study [39] showed that infections were no more frequent in the abatacept group than in the placebo group (37.6\% versus $32.3 \% ; P=0.30)$. Furthermore, the incidence of serious infections was $2.3 \%$ in both groups, with no unusual or opportunistic infections noted [39]. For the 6-month (double-blind) study and 18month (open-label) long-term extension of ATTAIN, respectively, the following adverse event rates were detected (per 100 patient-years) [45]: serious adverse events 34.5 and 29.4; malignancies 2.3 and 2.1 , and serious infections 4.6 and 3.7.

Reductions in immunoglobulin levels have been observed in some patients after repeat courses of rituximab, but in a pooled analysis of three randomized trials [69] mean values of both $\operatorname{lgG}$ and $\operatorname{lgM}$ remained well above the lower limit of normal (LLN). The percentage of patients with serum IgG or IgM levels below the LLN increased with the number of treatment courses, but the rate of serious infection for patients with low lgG/lgM levels was comparable to the rate in the overall population [69]. However, these numbers are low and warrant further observation. No opportunistic infections or cases of TB have been reported.

After 2,438 patient-years of exposure to rituximab, a total of 36 malignancies occurred in 32 patients (3\%) [68]. No lymphoproliferative malignancies and no increased risk for malignancy with additional courses of treatment with rituximab were observed. Eleven cases of lung cancer have been reported in the total abatacept safety database, as compared with the 3.5 to 12.3 expected based on RA DMARD cohorts, and with the 3.7 to 5.0 expected based on general population data [70]. More patient exposure and long-term safety monitoring are warranted to establish the safety profile of abatacept. The risk for activation of latent TB or for developing new TB when using abatacept is unknown [62]. However, before initiating abatacept, patients should be screened for latent TB infection with a tuberculin skin test [71]. Nevertheless, abatacept appears to have an acceptable safety profile so far.

A key tolerability concern is the safety of RA therapies, including TNF inhibitors and DMARDs, in patients with peripheral B-cell depletion after treatment with rituximab. Preliminary findings have indicated that the use of RA therapies (including TNF inhibitors) in patients who had received treatment with rituximab at a time when $B$-cell levels had yet to be normalized, did not result in development of 
opportunistic infections or a significant increase in serious adverse events [72]. Nevertheless, further investigation in larger numbers of patients over time is warranted.

\section{Conclusions}

Despite the therapeutic advance that TNF inhibitors have brought to RA treatment, more than $50 \%$ of patients fail to achieve at least an ACR50 response, and more lose response over time (secondary failure or acquired therapeutic resistance) or experience adverse events after treatment with TNF inhibitors. Observational studies have shown that some patients who have had an inadequate response to an initial TNF inhibitor do show an improvement in disease activity when switched to another TNF inhibitor. However, the type of inadequate response may be particularly important when considering the likelihood of response to a subsequent agent. The few observational studies that are available to address the issue of switching to another TNF inhibitor, in patients who previously failed one TNF blocker, clearly demonstrate that the majority of patients do not achieve an ACR50 response.

Rituximab and abatacept - new therapeutic agents with completely different modes of action - are now available for patients with inadequate response to a first TNF inhibitor. Evidence for the efficacy of switching to a second anti-TNF agent after failing to respond to an initial one most often relies on open, uncontrolled and nonrandomized studies, whereas biologics with a different mode of action have been evaluated in large randomized placebo-controlled trials. Randomized controlled head-to-head trials in this population would therefore be warranted to define the best treatment strategy in these patients. Cohort studies recently suggested that rituximab may be more effective than switching to an alternative TNF inhibitor in patients with an inadequate response to at least one TNF inhibitor $[55,56]$. These findings suggest that biologic agents with a different mode of action should be considered early as an alternative therapy after a first inadequate response to a TNF inhibitor. In the absence of randomized, prospective, head-to-head trials comparing available therapeutic options for patients exhibiting inadequate response or intolerance to a TNF inhibitor, the optimal treatment strategy is yet to be defined.

\section{Competing interests}

Dr Rubbert-Roth has received consultation fees and honoraria for presentations from Abbott, Essex, MSD, Roche, UCB and Wyeth. Dr Finckh has received support (in the form of consulting fees, grants or speaker fees) from Abbott, Centocor, Roche, Sanofi-Aventis and Wyeth. Drs RubbertRoth and Finckh did not receive financial compensation for this review.

\section{Acknowledgements}

Medical writing support was provided by Andrew Thomson, Claire Snowball and Karen Poynton at Adelphi Communications during the preparation of this article, supported by F Hoffmann-La Roche Ltd. The authors were responsible for critical revisions of the manuscript and for important intellectual content.

This article is published as Arthritis Research \& Therapy Volume 11 Supplement 1, 2009: Treatment options in patients with rheumatoid arthritis failing initial TNF inhibitor therapy: a critical review. The article is available online at http://arthritis-research.com/supplements/11/S1.

Publication of this supplement has been sponsored by F. Hoffmann-La Roche.

\section{References}

1. Lee DM, Weinblatt ME: Rheumatoid arthritis. Lancet 2001, 358: 903-911.

2. Gabriel SE, Crowson CS, Kremers HM, Doran MF, Turesson C, O'Fallon WM, Matteson EL: Survival in rheumatoid arthritis: a population-based analysis of trends over $\mathbf{4 0}$ years. Arthritis Rheum 2003, 48:54-58.

3. Mikuls TR, Saag KG, Criswell LA, Merlino LA, Kaslow RA, Shelton $\mathrm{BJ}$, Cerhan JR: Mortality risk associated with rheumatoid arthritis in a prospective cohort of older women: results from the lowa Women's Health Study. Ann Rheum Dis 2002, 61: 994-999.

4. Pincus T, Kavanaugh A, Sokka T: Benefit/risk of therapies for rheumatoid arthritis: underestimation of the 'side effects' or risks of RA leads to underestimation of the benefit/risk of therapies. Clin Exp Rheumato/ 2004, 22(suppl 35):S2-S11.

5. Emery P, Genovese MC, Kavanaugh AF, Cohen SB, Perez JL, Sasso EH: Adalimumab plus methotrexate results in less frequent and less severe radiographic progression than methotrexate alone at all levels of clinical response in early rheumatoid arthritis [abstract]. Ann Rheum Dis 2006, 65 (suppl II):88.

6. Smolen JS, van der Heijde DM, St Clair EW, Emery P, Bathon JM, Keystone E, Maini RN, Kalden JR, Schiff M, Baker D, Han C, Han $\mathrm{J}$, Bala M: Predictors of joint damage in patients with early rheumatoid arthritis treated with high-dose methotrexate with or without concomitant infliximab: results from the ASPIRE trial. Arthritis Rheum 2006, 54:702-710.

7. Strand V, Cohen S, Schiff M, Weaver A, Fleischmann R, Cannon G, Fox R, Moreland L, Olsen N, Furst D, Caldwell J, Kaine J, Sharp J, Hurley F, Loew-Friedrich I: Treatment of active rheumatoid arthritis with leflunomide compared with placebo and methotrexate. Leflunomide Rheumatoid Arthritis Investigators Group. Arch Intern Med 1999, 159:2542-2550.

8. Bathon JM, Martin RW, Fleischmann RM, Tesser JR, Schiff MH, Keystone EC, Genovese MC, Wasko MC, Moreland LW, Weaver AL, Markenson J, Finck BK: A comparison of etanercept and methotrexate in patients with early rheumatoid arthritis. $N$ Engl J Med 2000, 343:1586-1593.

9. Breedveld FC, Weisman MH, Kavanaugh AF, Cohen SB, Pavelka K, van Vollenhoven R, Sharp J, Perez JL, Spencer-Green GT: The PREMIER study: a multicenter, randomized, double-blind clinical trial of combination therapy with adalimumab plus methotrexate versus methotrexate alone or adalimumab alone in patients with early, aggressive rheumatoid arthritis who had not had previous methotrexate treatment. Arthritis Rheum 2006, 54:26-37.

10. Klareskog L, van der Heijde D, de Jager JP, Gough A, Kalden J, Malaise M, Mola EM, Pavelka K, Sany J, Settas L, Wajdula J, Pedersen R, Fatenejad S, Sanda M: Therapeutic effect of the combination of etanercept and methotrexate compared with each treatment alone in patients with rheumatoid arthritis: doubleblind randomised controlled trial. Lancet 2004, 363:675-681.

11. Lipsky PE, van der Heijde DM, St Clair EW, Furst DE, Breedveld FC, Kalden JR, Smolen JS, Weisman M, Emery P, Feldmann M, Harriman GR, Maini RN: Infliximab and methotrexate in the treatment of rheumatoid arthritis. Anti-Tumor Necrosis Factor Trial in Rheumatoid Arthritis with Concomitant Therapy Study Group. N Engl J Med 2000, 343:1594-1602.

12. Maini R, St Clair EW, Breedveld F, Furst D, Kalden J, Weisman M, Smolen J, Emery P, Harriman G, Feldmann M, Lipsky P: Infliximab (chimeric anti-tumour necrosis factor $\alpha$ monoclonal antibody) versus placebo in rheumatoid arthritis patients receiving concomitant methotrexate: a randomised phase III trial. ATTRACT Study Group. Lancet 1999, 354:1932-1939. 
13. Weinblatt ME, Kremer JM, Bankhurst AD, Bulpitt KJ, Fleischmann RM, Fox RI, Jackson CG, Lange M, Burge DJ: A trial of etanercept, a recombinant tumor necrosis factor receptor:Fc fusion protein, in patients with rheumatoid arthritis receiving methotrexate. N Engl J Med 1999, 340:253-259.

14. Weinblatt ME, Keystone EC, Furst DE, Moreland LW, Weisman $\mathrm{MH}$, Birbara CA, Teoh LA, Fischkoff SA, Chartash EK: Adalimumab, a fully human anti-tumor necrosis factor $\alpha$ monoclonal antibody, for the treatment of rheumatoid arthritis in patients taking concomitant methotrexate: the ARMADA trial. Arthritis Rheum 2003, 48:35-45.

15. Smolen J, Kay J, Doyle MK, Landewe R, Matteson EL, Wollenhaupt J, Gaylis N, Murphy F, Neal J, Zamani O, Zhou Y, Visvanathan S, Hsia EC, Rahman MU: Golimumab, a new human anti-TNF-alpha monoclonal antibody, subcutaneously administered every 4 weeks in patients with active rheumatoid arthritis who were previously treated with anti-TNF-alpha agent(s): results of the randomized double-blind, placebo-c (sic) [abstract]. Ann Rheum Dis 2008, 67(suppl II):50.

16. Tracey D, Klareskog L, Sasso EH, Salfeld JG, Tak PP: Tumor necrosis factor antagonist mechanisms of action: a comprehensive review. Pharmacol Ther 2008, 117:244-279.

17. Landewe R, Smolen J, Keystone EC, van Vollenhoven R, van der Heijde D: Radiographic inhibition of progression of structural damage: results from the RAPID 2 trial. Ann Rheum Dis 2008, 67(suppl II):321.

18. van der Heijde D, Weinblatt M, Landewe R, Goel N, Wells F, Fleischmann RM: Early inhibition of progression of structural damage in certolizumab pegol-treated patients: 16-week efficacy results from RAPID. Ann Rheum Dis 2008, 67(suppl II):51.

19. Finckh A, Simard JF, Gabay C, Guerne PA: Evidence for differential acquired drug resistance to anti-TNF agents in rheumatoid arthritis. Ann Rheum Dis 2008, 67:746-752.

20. Radstake T, Svenson M, Eijsbouts AM, van den Hoogen FHJ, Enevold C, van Riel P, Bendtzen K: Formation of antibodies against infliximab and adalimumab strongly correlates with functional drug levels and clinical responses in rheumatoid arthritis. Ann Rheum Dis 2008 [Epub ahead of print].

21. Kamal KM, Madhavan SS, Hornsby JA, Miller LA, Kavookjian J, Scott V: Use of tumor necrosis factor inhibitors in rheumatoid arthritis: a national survey of practicing United States rheumatologists. Joint Bone Spine 2006, 73:718-724.

22. Summary of product characteristics: MabThera $100 \mathrm{mg}$ and $500 \mathrm{mg}$ concentrate for solution for infusion. [http://emc.medicines.org.uk/emc/assets/c/html/ DisplayDoc.asp?DocumentID=2570]

23. Emery P, Keystone E, Cantagrel A, van Vollenhoven R, Sanchez A, Alecock E, Lee J, Kremer J: Tocilizumab (TCZ) significantly improves disease outcomes in patients with rheumatoid arthritis whose anti-TNF therapy failed: the RADIATE study [abstract]. Ann Rheum Dis 2008, 67(suppl II):127.

24. van Vollenhoven RF: Switching between anti-tumour necrosis factors: trying to get a handle on a complex issue. Ann Rheum Dis 2007, 66:849-851.

25. Bombardieri S, Ruiz AA, Fardellone $P$, Geusens $P$, McKenna $F$, Unnebrink K, Oezer U, Kary S, Kupper H, Burmester GR: Research in Active Rheumatoid Arthritis (ReAct) Study Group: effectiveness of adalimumab for rheumatoid arthritis in patients with a history of TNF-antagonist therapy in clinical practice. Rheumatology (Oxford) 2007, 46:1191-1199.

26. Keystone EC, Perruquet JL Lidham RW, Stein B, Pellar JS, Xia $H A$, Eickenhorst T: Switching anti-TNF therapy: real world outcome of patients with rheumatoid arthritis who failed either infliximab or etanercept of treatment and switched to another TNF inhibitor [abstract]. Arthritis Rheum 2004, 50 (suppl):S400-S401.

27. Kristensen LE, Saxne T, Geborek P: The LUNDEX, a new index of drug efficacy in clinical practice: results of a five-year observational study of treatment with infliximab and etanercept among rheumatoid arthritis patients in southern Sweden. Arthritis Rheum 2006, 54:600-606.

28. Kristensen LE, Saxne T, Geborek P: Switching between antiTNF therapies does not affect level of adherence to therapy in rheumatoid arthritis but response rates seem to decline. [abstract]. Ann Rheum Dis 2006, 65(suppl II):327.

29. Navarro F, Gomez-Reino JJ, Marsal S: EULAR response in clinical practice in RA patients treated with one, two or three anti-
TNF alpha agents: results of an observational, prospective, cohort study in Spain [abstract]. Arthritis Rheum 2006, 54 (suppl II):S384.

30. Yazici Y, Erkan D: Do etanercept-naive patients with rheumatoid arthritis respond better to infliximab than patients for whom etanercept has failed? Ann Rheum Dis 2004, 63:607608.

31. Karlsson JA, Kristensen LE, Kapetanovic MC, Gulfe A, Saxne T, Geborek P: Treatment response to a second or third TNFinhibitor in RA: results from the South Swedish Arthritis Treatment Group Register. Rheumatology (Oxford) 2008, 47: 507-513.

32. Furst DE, Gaylis N, Bray V, Olech E, Yocum D, Ritter J, Weisman M, Wallace D, Crues J, Khanna D, Eckel G, Yeilding N, Callegari P, Visvanathan S, Rojas J, Hegedus R, George L, Mamun K, Gilmer K, Troum O: Open-label, pilot protocol of patients with rheumatoid arthritis who switch to infliximab after an incomplete response to etanercept: The OPPOSITE study. Ann Rheum Dis 2007, 66:893-899.

33. Hyrich KL, Lunt M, Watson KD, Symmons DPM, Silman AJ, Furstenberg CT: Outcomes after switching from one antitumor necrosis factor $\alpha$ agent to a second anti-tumor necrosis factor $\alpha$ agent in patients with rheumatoid arthritis: results from a large UK national cohort study. Arthritis Rheum 2007, 56:13-20.

34. Blom M, Kievit W, Fransen J, Kuper IH, van der Laar M, de Rooj D, de Gendt $C$, Jansen TL: Effectiveness of a switch to a second anti-TNF- $\alpha$ in primary nonresponders, secondary nonresponders and failure due to adverse events [abstract]. Arthritis Rheum 2007, 56(suppl):S165.

35. Gullick N, Da Silva C, Kirkham B: Failure of adalimumab in patients with rheumatoid arthritis [abstract]. Arthritis Rheum 2007, 56(suppl):S183.

36. Buch $\mathrm{MH}$, Bingham SJ, Bryer D, Emery P: Long-term infliximab treatment in rheumatoid arthritis: subsequent outcome of initial responders. Rheumatology (Oxford) 2007, 46:1153-1156.

37. Gomez-Reino JJ, Carmona L: Switching TNF antagonists in patients with chronic arthritis: an observational study of 488 patients over a four-year period. Arthritis Res Ther 2006, 8: R29.

38. Kishimoto M, Greenberg J, Abramson SB, Harrington T, Olenginski TP, Kafka SP, Reed G, Hinkle K, Kremer J, Cohen SB: Drug survival time on anti-TNF agents: does prior anti-TNF use influence RA outcomes? [Abstract]. Arthritis Rheum 2005, 52 (suppl):S347.

39. Genovese MC, Becker JC, Schiff $M$, Luggen $M$, Sherrer $Y$, Kremer J, Birbara C, Box J, Natarajan K, Nuamah I, Li T, Aranda R, Hagerty DT, Dougados M: Abatacept for rheumatoid arthritis refractory to tumor necrosis factor alpha inhibition. $N$ Engl $J$ Med 2005, 353:1114-1123.

40. Cohen SB, Emery P, Greenwald MW, Dougados M, Furie RA, Genovese MC, Keystone EC, Loveless JE, Burmester GR, Cravets MW, Hessey EW, Shaw T, Totoritis MC: Rituximab for rheumatoid arthritis refractory to anti-tumor necrosis factor therapy: results of a multicenter, randomized, double-blind, placebo-controlled, Phase III trial evaluating primary efficacy and safety at twenty-four weeks. Arthritis Rheum 2006, 54: 2793-2806

41. Kremer JM, Tony HP, Genovese MC, Tak PP, Luggen M, Bombardieri S, Hessey E, Safa-Leathers S: Repeat treatment with rituximab in active RA patients: long-term efficacy in patients with one versus two or more prior TNF inhibitors. Ann Rheum Dis 2007, 66(suppl):432.

42. Kremer JM, Tony HP, Tak PP, Luggen M, Mariette X, Hessey E, McCabe D, Safa-Leathers S: Efficacy of rituximab in active RA patients with an inadequate response to one or more TNF inhibitors. Ann Rheum Dis 2006, 65(suppl II):326.

43. van Vollenhoven R, Cullinane Carli C, Augustsson J, Klareskog L: Experience with rituximab in the treatment of rheumatoid arthritis (RA): results from the Sture Registry [abstract]. Ann Rheum Dis 2008, 67(suppl II):340.

44. Keystone E, Fleischmann RM, Emery P, Chubick A, Dougados M Baldassare AR, Bathon JM, Hessey E, Hagerty D, Cooper S: Repeated treatment courses of rituximab in rheumatoid arthritis: sustained efficacy in patients with an inadequate response to one or more TNF inhibitors [abstract]. Ann Rheum Dis 2007, 66(suppl II):432. 
45. Genovese MC, Schiff $M$, Luggen $M$, Becker JC, Aranda $R$, McCann T, Schmidely N, Le Bars M, Dougados M: Sustained efficacy and safety through 2 years in patients with rheumatoid arthritis (RA) in the long-term extension of the ATTAIN trial [abstract]. Arthritis Rheum 2006, 54(suppl):S244.

46. Hyrich $\mathrm{K}$, Lunt M, Dixon WG, Watson KD, Symmons DPM: Effects of switching between anti-TNF therapies on HAQ response in patients who do not respond to their first antiTNF drug. Rheumatology (Oxford) 2008, 47:1000-1005.

47. Aletaha D, Smolen J, Ward MM: Measuring function in rheumatoid arthritis: identifying reversible and irreversible components. Arthritis Rheum 2008, 54:2784-2792.

48. Keystone E, Burmester GR, Furie R, Loveless JE, Emery P, Kremer J, Tak PP, Broder MS, Yu E, Cravets M, Magrini F, Jost F: Improvement in patient-reported outcomes in a rituximab trial in patients with severe rheumatoid arthritis refractory to antitumor necrosis factor therapy. Arthritis Rheum 2008, 59:785793.

49. Keystone EC, Emery P, Peterfy CG, Tak PP, Cohen S, Genovese MC, Dougados M, Burmester GR, Greenwald M, Kvien TK, Williams S, Hagerty D, Cravets MW, Shaw T: Rituximab inhibits structural joint damage in rheumatoid arthritis patients with an inadequate response to tumour necrosis factor inhibitor therapies. Ann Rheum Dis 2009, 68:216-221.

50. Cohen S, Keystone E, Genovese M, Emery P, Peterfy C, Tak PP, Cravets M, Shaw T, Hagerty D: Continued inhibition of structural damage in rheumatoid arthritis patients treated with rituximab at 2 years: Reflex study [abstract]. Ann Rheum Dis 2008, 67(suppl II):189.

51. Keystone EC, Emery P, Peterfy CG, Tak PP, Cohen SB, Genovese MC, Williams S, Cravets MW, Hagerty D, Shaw T: Inhibition of radiographic progression with rituximab is not dependent on clinical efficacy: results from a study in rheumatoid arthritis patients with an inadequate response to one or more TNF inhibitors (REFLEX) [abstract]. Ann Rheum Dis 2007, 66(suppl II):431.

52. Smolen JS, Han C, Bala M, Maini RN, Kalden JR, van der Heijde D, Breedveld FC, Furst DE, Lipsky PE: Evidence of radiographic benefit of treatment with infliximab plus methotrexate in rheumatoid arthritis patients who had no clinical improvement: a detailed subanalysis of data from the anti-tumor necrosis factor trial in rheumatoid arthritis with concomitant therapy study. Arthritis Rheum 2005, 52:1020-1030.

53. Kremer JM, Genant HK, Moreland LW, Russell AS, Emery P, Abud-Mendoza C, Szechiñski J, Li T, Ge Z, Becker JC, Westhovens R: Effects of abatacept in patients with methotrexateresistant active rheumatoid arthritis: a randomized trial. Ann Intern Med 2006, 144:865-876.

54. Finckh A, Ciurea A, Brulhart L, Kyburz D, Mõller B, Dehler S, Revaz S, Dudler J, Gabay C, O'Brien S: B cell depletion may be more effective than switching to an alternative anti-tumor necrosis factor agent in rheumatoid arthritis patients with inadequate response to anti-tumor necrosis factor agents. Arthritis Rheum 2007, 56:1417-1423.

55. Finckh A, Ciurea A, Brulhart L, Moeller B, Walker UA, Courvoisier $D$, Kyburz D, Gabay C: Which subgroup of rheumatoid arthritis patients benefit most from switching to rituximab versus alternative anti-TNF agents after previous failure to anti-TNF agents? [Abstract]. Ann Rheum Dis 2008, 67(suppl II):127.

56. Venkatachalam S, Roskell S, Suchitra R, Price T, Mulherin D, Sheeran T: Rituximab may be more effective than switching to an alternative TNF inhibitor in rheumatoid arthritis patients who have failed other TNF inhibitors. Rheumatology (Oxford) 2008, 47:ii28.

57. Hochberg MC, Lebwohl MG, Plevy SE, Hobbs KF, Yocum DE: The benefit/risk profile of TNF-blocking agents: findings of a consensus panel. Semin Arthritis Rheum 2005, 34:819-836.

58. Imperato AK, Bingham CO III, Abramson SB: Overview of benefit/risk of biological agents. Clin Exp Rheumatol 2004, 22 (suppl 35):S108-S114.

59. Wolfe F, Michaud K: Lymphoma in rheumatoid arthritis: the effect of methotrexate and anti-tumor necrosis factor therapy in 18,572 patients. Arthritis Rheum 2004, 50:1740-1751.

60. Wolfe F, Michaud K: Biologic treatment of rheumatoid arthritis and the risk of malignancy: analyses from a large US observational study. Arthritis Rheum 2007, 56:2886-2895.

61. Bongartz T, Sutton AJ, Sweeting MJ, Buchan I, Matteson EL,
Montori V: Anti-TNF antibody therapy in rheumatoid arthritis and the risk of serious infections and malignancies: systematic review and meta-analysis of rare harmful effects in randomized controlled trials. JAMA 2006, 295:2275-2285.

62. Furst DE, Breedveld FC, Kalden JR, Smolen JS, Burmester GR, Sieper J, Emery P, Keystone EC, Schiff MH, Mease P, van Riel PL, Fleischmann R, Weisman MH, Weinblatt ME: Updated consensus statement on biological agents for the treatment of rheumatic diseases, 2007. Ann Rheum Dis 2007, 66(suppl 3): iii2-iii22.

63. Mackey AC, Green L, Liang LC, Dinndorf P, Avigan M: Hepatosplenic $T$ cell lymphoma associated with infliximab use in young patients treated for inflammatory bowel disease. $J$ Pediatr Gastroenterol Nutr 2007, 44:265-267.

64. Wegener's Granulomatosis Etanercept Trial (WGET) Research Group: Etanercept plus standard therapy for Wegener's granulomatosis. N Engl J Med 2002, 61:351-361.

65. Askling J, Fored CM, Brandt L, Baecklund E, Bertilsson L, Feltelius N, Coster L, Geborek P, Jacobsson LT, Lindblad S, Lysholm J, Rantapää-Dahlqvist S, Saxne T, van Vollenhoven RF, Klareskog $L$ : Time-dependent increase in risk of hospitalisation with infection among Swedish RA patients treated with TNF antagonists. Ann Rheum Dis 2007, 66:1339-1344.

66. Dixon W, Watson K, Hyrich K, Lunt M, Silman A, Symmons D: The incidence of serious infections is not increased in patients with rheumatoid arthritis treated with anti-TNF drugs compared to those treated with traditional DMARDs: results from a national prospective study [abstract]. Arthritis Rheum 2006, 52(suppl):S738

67. Listing J, Strangfeld A, Kary S, Rau R, von HU, Stoyanova-Scholz M, Gromnica-Ihle E, Antoni C, Herzer P, Kekow J, Schneider M, Zink A: Infections in patients with rheumatoid arthritis treated with biologic agents. Arthritis Rheum 2005, 52:3403-3412.

68. van Vollenhoven RF, Emery P, Bingham CO III, Keystone E, Greenwald M, Moreland LW, Sweetser M, Rowe K, Wagner B, Magrini F: Extended follow-up of the long-term safety of rituximab in rheumatoid arthritis [abstract]. Arthritis Rheum 2007, 56(suppl):S147-S148.

69. Genovese M, Emery $P$, Ruderman E, Keystone E, Furst D, van Vollenhoven R, Sweetser M, Magrini F, Tindall E, Shaw T, Yocum $D$ : Immunoglobulin levels and infection rates in patients with rheumatoid arthritis treated with repeated courses of rituximab [abstract]. Arthritis Rheum 2007, 56(suppl):S149.

70. Simon TA, Smitten AL, Boodhoo T, Askling J, Franklin J, Lecaille $D$, Wolfe F: Observed and expected malignancies in the abatacept clinical development program: an epidemiological assessment [abstract]. Ann Rheum Dis 2006, 65(suppl II): 489.

71. Orencia ${ }^{\circledR}$ [abatacept] prescribing information. [http://www. bms.com/cgi-bin/anybin.pl?sql=select $\% 20 \mathrm{PPI} \% 20$ from $\% 20$ TB_PRODUCT_PPI\%20where\%20PPI_SEQ=111\&key=PPI]

72. Genovese MC, Breedveld FC, Emery P, Moreland LW, Keystone EC, Matteson EL, Baptiste Y, Burke L, Reiss W, Sweetser M, Shaw T: Safety of TNF inhibitors and non-biologic DMARDs in rheumatoid arthritis patients previously treated with rituximab [abstract]. Arthritis Rheum 2007, 56(suppl):S150. 